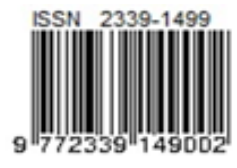

Paper ini telah di review dan dipublikasikan di Jurnal Rekayasa Sistem Industri Volume 7 No 1 April 2018

http://journal.unpar.ac.id/index.php/irsi/index

ISSN 2339-1499 (online)

\title{
Analisis Pemanfaatan RFID terhadap Efisiensi Biaya dalam Global Supply Chain Management
}

\author{
Yustina Tritularsih ${ }^{1,2}$, Wahyudi Sutopo ${ }^{3}$ \\ 1)Mahasiswa Program Studi Magister Teknik Industri, Universitas Sebelas Maret Surakarta, \\ JI. Ir. Sutami No. 36A, Kentingan, Surakarta, 57126 \\ ${ }^{2\}}$ Staf pengajar Program Studi Teknik Mekatronika, Politeknik ATMI Surakarta, \\ Jl. Adisucipto/ JI. Mojo No.1, Laweyan Surakarta, 57145 \\ 3) Program Studi Teknik Industri, Fakultas Teknik, Universitas Sebelas Maret Surakarta, \\ JI. Ir. Sutami No. 36A, Kentingan, Surakarta, 57126, Indonesia \\ Email: yustina_tritularsih@atmi.ac.id, wahyudisutopo@staff.uns.ac.id
}

\begin{abstract}
Supply Chain Management (SCM) has been assumed to play an important role in the company's performance and has attracted academician's attention to research seriously in these recent years. A number of literatures reveal the research of supply chain management developmenth that has implemented RFID technology. Generally, the method is implemented by combining and informing the journal about cost-benefit analysis model in a company that applies RFID tag technology integratedly from production line, delivery up to management of retailer part. Currently, all links from the entire supply chain need to integrate those different parts and have better controls to get better returns. This integration must offer the ability for the company to have a thorough and transparent insight into its supply chain activities. Intelligent supply chains that are primarily supported by RFID technology can meet these integration needs. By using RFID, a company can benefit from several advantages. One of them is cost reduction and time efficiency. This paper attempts to recommend a model to estimate the benefits of implementing RFID in companies that have an integrated supply chain process. The proposed model is used to find out the value of depreciation and RFID price tag that can provide maximum benefit from RFID implementation. Examples of case studies provide a better understanding of calculation model
\end{abstract}

Keywords: Supply Chain Management, RFID, integrated, efficiency, cost advantage.

\begin{abstract}
Abstrak
Supply Chain Management (SCM) telah diasumsikan ikut berperan penting dalam kinerja perusahaan dan telah menarik perhatian pihak akademis untuk melakukan penelitian yang serius selama beberapa tahun terakhir ini. Sejumlah tinjauan literatur banyak mengungkapkan dalam studi literaturnya tentang penelitian perkembangan supply chain management yang telah mengimplementasikan teknologi RFID. Metode yang dilakukan umumnya dengan menggabungkan dan menginformasikan pada jurnal tentang model analisis keuntungan biaya pada sebuah perusahaan yang menerapkan teknologi RFID yang terintegrasi mulai dari lini produksi, pengiriman sampai pada pengelolaan bagian pengecernya. Saat ini semua link dari keseluruhan rantai pasokan perlu mengintegrasikan infrastruktur yang berbeda dan memiliki kontrol yang lebih baik untuk mendapatkan keuntungan yang lebih baik. Integrasi ini harus menawarkan kemampuan bagi perusahaan untuk memiliki wawasan menyeluruh dan transparan terhadap aktivitas rantai pasokannya. Sistem Global Rantai pasokan cerdas yang didukung oleh teknologi RFID dapat memenuhi kebutuhan integrasi tersebut. Dengan menggunakan RFID, sebuah perusahaan bisa mendapatkan keuntungan dari beberapa keuntungan. Salah satunya adalah pengurangan biaya dan efisiensi waktu. Makalah ini mencoba untuk merekomendasikan sebuah model untuk memperkirakan manfaat penerapan RFID di perusahaan yang memiliki proses rantai pasokan terpadu. Model yang diusulkan digunakan untuk mengetahui nilai penyusutan dan harga tag RFID yang dapat memberikan manfaat maksimal dari implementasi RFID. Contoh studi kasus juga diberikan untuk memberikan pemahaman yang lebih baik mengenai perhitungan model.
\end{abstract}

Kata kunci: Supply Chain Management, RFID, terintegrasi, efisiensi, keuntungan biaya. 


\section{Pendahuluan}

Manajemen rantai pasok atau supply chain management (SCM) saat ini telah menjadi bagian yang terpenting dalam perusahaan dan subyek kajian dalam penelitian keilmuan teknik industri untuk mengatasi persoalan yang semakin komplek. Perusahaan ditantang dengan menemukan cara untuk memenuhi harapan pelanggan yang terus meningkat dengan penekanan biaya yang dikelola. Untuk melakukannya, perusahaan harus mencari bagian mana dari proses rantai pasok mereka yang tidak kompetitif, melihat kebutuhan pelanggan yang tidak terpenuhi dan menetapkan tujuan perbaikan, serta secepatnya menerapkan perbaikan yang diperlukan.

Telah diketahui sebelumnya bahwa produsen adalah mata rantai supply yang mengelola produk yang diproduksi dan didistribusikan secara cepat. Dengan adanya teknologi informasi saat ini pelanggan merupakan aspek bisnis yang paling penting, dan produsen berebut untuk memenuhi permintaan pelanggan untuk pilihan, gaya, fitur, urutan pemenuhan dan pengiriman dengan cepat, produk manufaktur yang berkualitas, sehingga memenuhi tuntutan spesifik pelanggan untuk pengiriman produk telah menjadi keunggulan kompetitif. Perusahaan yang berusaha untuk meningkatkan manajemen rantai pasok mereka, akan mampu menghadapi persaingan di pasar global. Melalui pengamatan dan hasil penelitian dalam jurnal beberapa menunjukkan perbedaan biaya yang signifikan antara perusahaan yang menunjukkan kinerja yang terbaik di kelasnya dan dengan kinerja ratarata.

Secara tradisional, SCM telah menjadi peleburan dari berbagai aspek, dengan pengaruh dari logistik dan transportasi, manajemen operasi dan bahan dan manajemen distribusi, pemasaran, serta pembelian. Dengan bergesernya era tradisional menuju era teknologi digital seluruh aktivitas tersebut didukung dengan adanya teknologi informasi dan komunikasi.
Dukungan teknologi informasi ini menjadi salah satu strategi saat ini untuk mewujudkan terciptanya efisiensi, keterpaduan, dan pengendalian barang secara optimal dalam global supply chain management. Sebagai salah satu bentuk penerapan teknologi tersebut yaitu penggunaan RFID (Radio Frequency Indentification) yang mampu meningkatkan produktivitas, monitoring control produk dan peningkatan mobilitas produk. RFID merupakan perkembangan dari teknologi barcode yang memberikan informasi secara lebih detail pada suatu produk dan dapat diintegrasikan pada database, diantaranya :

1. Memberikan informasi tentang produk baik itu spesifikasi, status produk dan jumlah

2. Memberikan informasi dari isi produk

3. Memberikan informasi inventory control

Penelitian ini bertujuan untuk mengkaji penerapan RFID dalam SCM untuk pengelolaan persediaan produk di retailer dengan memperhatikan aspek masalah penyusutan, maka dalam penelitian ini dikembangkan model analisis keuntungan biaya pada perusahaan yang menerapkan teknologi RFID secara terintegrasi mulai dari lini produksi, pengiriman sampai pada pengelolaan bagian retailer.

\section{Kajian Pustaka}

\section{Radio Frequency Identification (RFID)}

$R F I D$ merupakan teknologi pengambilan data secara elektronik untuk mengidentifikasi informasi yang tersimpan di dalam tag menggunakan frekuensi radio secara otomatis. RFID merupakan perkembangan teknologi dari barcode. Menurut Juels (2005) menyatakan bahwa teknologi ini memliki perbedaan karakteristik antara barcode dan RFID. Adapun perbedaan ini ditunjukkan pada Tabel 1. 
Tabel 1. Perbedaan Karakteristik Barcode dan RFID (Sumber : Veronneau S, 2009)

\begin{tabular}{|c|c|c|}
\hline & Garcode & Sropest \\
\hline Vondsi pentacaan & Jine of $S$; & "1nkes \\
\hline Posis pentacazn & 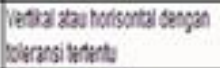 & Betos, segala botsi nementh \\
\hline \multirow[t]{2}{*}{ Racepatas penbocan } & 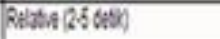 & c100milster \\
\hline & & perten \\
\hline \multirow[t]{3}{*}{ Jerek neksinun pembocan } & :7 ca isendely & : 30 on ipendely \\
\hline & & : 3m (menengat) \\
\hline & & $: 10 \mathrm{~m}(\mathrm{jaz})$ \\
\hline Kematwar & 8acaseda & Sca donasulis \\
\hline Kapustas memon & Ked & 360 atulabs \\
\hline Proses pertbocan & $\begin{array}{l}\text { Per tan momorsessibipe } \\
\text { ot }\end{array}$ & 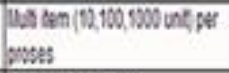 \\
\hline $\operatorname{con} d s$ & 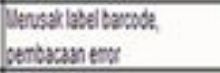 & Tiat berpengonth \\
\hline Remudatan dpilest & tutsh & Hangir nustitoil \\
\hline
\end{tabular}

Prinsip kerja dari sistem RFID adalah menjalankan proses pembacaan frekuensi radio yang tersimpan dalam tag, kemudian informasi yang diterima dikirim ke database. Jadi komponen utama RFID adalah tag, reader dan database. Sistem RFID bertujuan untuk mengidentifikasi secara otomatis data yang telah ditransmisikan oleh peralatan portable atau tag, kemudian data akan diproses oleh reader $R F I D$ untuk kebutuhan dari aplikasi tertentu. Adapun data yang ditransmisikan tersebut dapat memberikan informasi yang ada di dalamnya seperti lokasi, harga, warna, tanggal pembelian dan lain-lain. Sebagai komponen utama, tag adalah sebuah label identifikasi yang berisi potongan-potongan informasi yang dapat diprogram dan dikendalikan komputer tanpa harus membutuhkan direct line of sight seperti yang dimiliki barcode. Tag ini terdiri dari antena dan chips yang memiliki jangkauan reader sekitar satu meter. Untuk tipe memory terdiri dari jenis read only atau read write. Setiap tag memuat informasi yang dapat membantu proses pelacakan keberadaan sebuah produk. Tag ini diletakkan pada sebuah produk agar dapat diidentifikasi oleh sebuah reader kemudian data disinkronisasi dengan database komputer. Database ini dalam penerapan RFID berfungsi sebagai sumber informasi sistem logistik yang terhubung melalui jaringan LAN (Local Area Network) atau WAN (Wireless Area Network). Sedangkan frekuensi RFID berfungsi untuk komunikasi wireless antara reader dengan tag RFID. Pemilihan frekuensi berpengaruh terhadap jarak komunikasi, interferensi terhadap frekuensi radio lain, kecepatan komunikasi data dan ukuran antena.

Ada beberapa band yang digunakan untuk sistem $R F I D$, yaitu frekuensi tinggi dan frekuensi rendah. Frekuensi tinggi digunakan untuk tag aktif yang dapat mentransmisikan data dengan jarak jauh sedangkan frekuensi rendah digunakan untuk tag pasif yang dapat menstramisikan data dengan jarak dekat karena daya yang diperoleh dari gelombang elektromagnetik. Untuk menstranmisikan gelombang elektromagnetik tergantung dari ukuran antenna, untuk frekuensi rendah harus dibuat ukuran antenna yang lebih besar dibandingkan dengan ukuran antenna frekuensi tinggi. Faktor keberhasilan dan keakuratan data dalam pengambilan data dari proses identifikasi yang dilakukan tag sangat berpengaruh terhadap beberapa batasan fisik yaitu posisi antena reader, karakteristik material dari lingkungan yang mencakup sistem RFID, batasan catu daya, dan frekuensi kerja RFID (Hunt, 2007).

\section{Model Integrasi Supply Chain Management}

Rantai pasok terpadu diilustrasikan pada Gambar 1. Dimulai dengan titik A, item dikemas dalam kotak atau kardus dan dimuat ke palet - keduanya memiliki tag sendiri untuk memberikan visibilitas yang lebih baik dan untuk melacak jalur pergerakan barang secara akurat. Ketika palet meninggalkan pabrik, reader RFID di dermaga pemuatan dengan cepat membaca semua tag item secara serial. Informasi ini dikirim ke komputer. Sistem sekarang tahu barang mana yang diproduksi dimana dan kapan (titik A pada Gambar 1). Informasi yang sama tersedia untuk distributor ketika barang yang sampai di sana dibaca oleh reader di sisinya (titik B pada Gambar 1 ). Item dengan cepat diarahkan ke truk yang sesuai (titik C). Saat barang-barang ini sampai di outlet ritel, barang-barang tersebut dibaca oleh reader dermaga penerima dan persediaannya diperbarui secara otomatis (titik D). Karena rak di outlet ini juga memiliki reader sendiri, maka secara otomatis item-item tersebut mengidentifikasi pesanan dan melakukan pengisian ulang di rak yang kosong. Urutan ini dapat diperluas ke meja kasir saat pelanggan menggunakan kartu RFID. Mereka hanya berjalan masuk ke toko dengan membawa 
pembeliannya. Seorang pembeli yang keluar dari pintu toko mengenali barang-barang yang diambil dan secara otomatis mendebet kartu RFID tersebut.

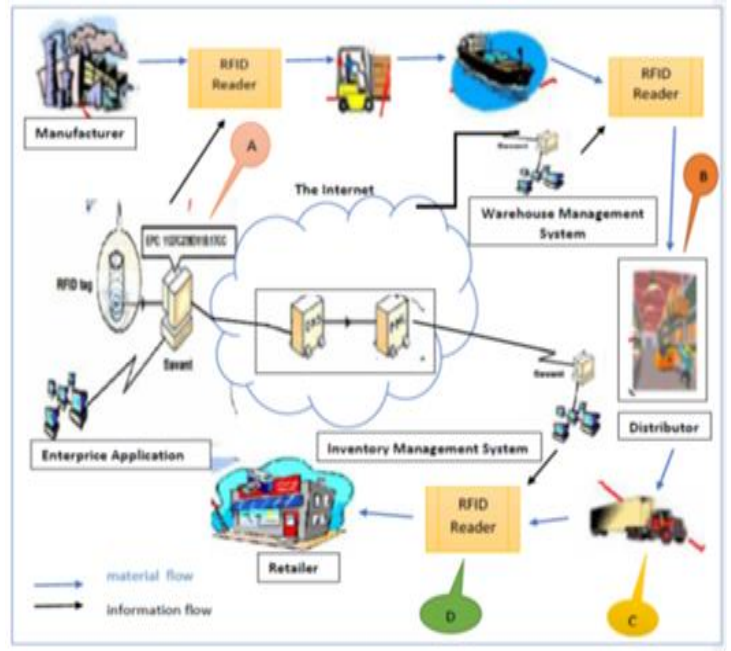

Gambar 1. Representasi Grafis Model Rantai Pasokan Terpadu (Sumber: Zaheeruddin, 2005).

\section{Keuntungan Pemanfaatan RFID pada sebuah perusahaan yang menerapkan teknologi RFID}

Berdasarkan dari sumber studi literatur terkait pemanfaaatan RFID, ditemukan jurnal yang menganalisis perbedaan teknologi dari beberapa tipe Smart Item. Ada 3 jenis smart item yang sering digunakan perusahaan, diantaranya adalah barcode, RFID, dan sensor network (Gambar.1). Barcode hanya bisa melakukan identifikasi tentang ketepatan informasi data angka pada sebuah produk. RFID bisa bekerja lebih baik dari barcode, yaitu bisa mengidentifikasi barang dengan tepat, jumlah yang tepat dan mengidentifikasi lokasi barang dengan tepat. Sedangkan sensor network memiliki kemampuan yang lebih baik dibanding keduanya. Selain kelebihan yang dimiliki RFID, sensor network dapat melakukan identifikasi jumlah, melaporkan perubahan secara real time, dan dapat mengidentifikasi harga guna melakukan optimasi (Decker dkk, 2008).

Berdasarkan jurnal pertama (Decker dkk, 2008), diketahui latar belakang penulisan yaitu penerapan teknologi Smart Item pada proses supply chain yang melibatkan pemasok, pengirim dan pelanggan sehingga dapat dipantau secara real time, sedangkan tujuan dari jurnal ini adalah untuk menganalisis perbedaan teknologi dari beberapa tipe Smart
Item dan mengembangkan model matematis untuk analisis keuntungan biaya terhadap penerapan RFID baik dari sisi pemasok, pengirim maupun pelanggan.

\begin{tabular}{|c|c|c|c|}
$\begin{array}{c}\text { Function } \\
\text { (Logistics) }\end{array}$ & $\begin{array}{c}\text { Techniques } \\
\text { (Information System) }\end{array}$ \\
\hline right goods & Technology and Coverage \\
(Smart Items)
\end{tabular}

Gambar 2. Jenis Smart Item dan fungsinya (Sumber : Decker, 2008).

Sedangkan menurut jurnal kedua (Fan dkk, 2014), memberikan penjelasan tentang faktor penyusutan mempengaruhi ketidakakuratan pengendalian persediaan pada retailer. Penerapan teknologi RFID dianggap sebagai solusi yang menjanjikan untuk mengatasi permasalahan tersebut. Maka dari itu, dalam makalah kedua ini dikembangkan model matematis yang dapat digunakan untuk menganalisis pengaruh penerapan RFID dalam mengurangi masalah penyusutan pada persediaan retailer. Peneliti pada jurnal ini menggunakan pendekatan model matematis dengan RFID yang bertujuan untuk mencari nilai jumlah order dan profit yang optimal.

\section{Metode Penelitian}

Penelitian ini mengembangkan model analisis keuntungan biaya pada perusahaan yang menerapkan teknologi RFID secara terintegrasi mulai dari lini produksi, pengiriman sampai pada pengelolaan bagian pengecer yang menggunakan urutan proses sebagai berikut :

1. Mengumpulkan jurnal tentang penerapan smart item (barcode, RFID, dan jaringan sensor).

2. Membandingkan antara jurnal tentang RFID yang sudah diimplementasikan di industri dan jurnal tentang keuntungan biaya pada perusahaan yang menggunakan RFID.

3. Dari kedua jurnal tersebut, peneliti 
mendapat masalah apakah ada perhitungan laba berdasarkan implementasi RFID tersebut.

4. Membuat contoh studi kasus untuk menggambarkan penggunaan model pengembangan,

5. Menganalisis studi kasus tersebut dan membuat grafik hasilnya.

6. Membuat kesimpulan.

\section{Hasil dan Pembahasan}

Tujuan dari penerapan teknologi RFID adalah mengkaji penerapan RFID dalam SCM untuk pengelolaan persediaan produk di retailer dengan memperhatikan aspek masalah penyusutan. Solusi RFID akan membantu menurunkan biaya operasional, meningkatkan throughput di pusat distribusi, memaksimalkan pengiriman tepat waktu dan meningkatkan layanan dan kepuasan pelanggan. RFID digunakan sebagai alat otomatis data dan alat informasi yang akurat sebagai optimasi kerja. Selain itu keunggulan dari RFID dapat meminimalisasi proses dalam pengontrolan produk. RFID sebagai media input data dalam serangkaian aktivitas logistic yang berfungsi sebagai alat komunikasi yang mampu membaca data produk dan mengubah stok produk yang pada akhirnya akan mengirimkan data ke database. Pembacaan RFID ini jauh lebih baik dibandingkan dengan barcode karena tanpa diperlukan arah penempatan yang persisi. Teknologi RFID ini mampu mengirimkan dan mengambil data dengan cepat dan otomatis secara akurat, spesifik dan tepat waktu.

Menurut penelitian Sarac dan Rekik (2009) menyatakan bahwa dengan penggunaan teknologi RFID diasumsikan dapat mengurangi resiko kerusakan produk sebesar $5 \%$ karena sistem ini mampu menerima informasi atau data dengan lebih akurat, cepat dan efisien. Penelitian lain juga dinyatakan oleh Tarigan (2004), bahwa RFID dapat mengurangi kesalahan yang diakibatkan oleh kelalaian manusia. Dengan meningkatkan visibilitas di seluruh rantai pasokan, keuntungan dari penerapan sistem $R F I D$ saat ini terbukti bermanfaat bagi industri.

Untuk melihat benefit dari penerapan RFID ini, solusi pendekatan model RFID ada tiga kategori; (i) Model konvensional, (ii) Model yang tidak pasti, (iii) Model pengambilan keputusan (Wu, 2009).

Untuk mendapatkan gambaran tentang penggunaan parameter pada pemodelan ini, maka contoh kasus dibuat untuk memudahkan proses pemahaman model.

\section{Contoh Kasus :}

Sebuah perusahaan $A B C$ bergerak di bidang distribusi dan penjualan produk buahbuahan yang berkualitas tinggi (premium). Perusahaan tersebut memiliki fasilitas layanan pengiriman dan sejumlah toko retail yang dimiliki perusahaan itu sendiri. Jalur supply chain pengiriman produk perusahaan tersebut telah dilengkapi dengan teknologi canggih Smart Item berupa RFID beserta infrastruktur sistem IT nya.

Produk buah apel premium yang dijual perusahaan tersebut memiliki data sebagaimana dapat dilihat pada Tabel 2.Tiap buah tersebut dipasang RFID tag. RFID tag yang ada di pasaran memiliki harga yang bervariasi dengan pengaruh improvement yang bervariasi pula. Sedangkan data dan biaya yang muncul dalam pengoperasian supply chain dengan sistem RFID dapat dilihat pada Tabel 3.

Tabel 2. Data Parameter RFID

\begin{tabular}{|c|c|c|c|}
\hline$c$ & producti on/box & \multicolumn{2}{|r|}{$\$ 10,00$} \\
\hline c & Production cost/unit & \multicolumn{2}{|r|}{$\$ 0,20$} \\
\hline$p$ & Harga Jual per unit & \multicolumn{2}{|r|}{2,50} \\
\hline$g$ & shortage cost & $\$$ & 0,50 \\
\hline s & salvage price & \multirow[t]{2}{*}{$\$$} & 1,00 \\
\hline \multicolumn{2}{|c|}{$\beta$ demand } & & 20.000 \\
\hline$\alpha$ & \multicolumn{2}{|c|}{$\begin{array}{l}\text { produk yang tersedia di toko } \\
\text { (setelah shrinkage) }\end{array}$} & 0,80 \\
\hline b & \multicolumn{2}{|l|}{ RFID improve ment rate } & sesuai tipe tag \\
\hline
\end{tabular}


Tabel 3. Parameter biaya $R F I D$

\begin{tabular}{|l|l|l|}
\hline 1 pallet & 10 & box \\
\hline 1 box & 50 & pcs \\
\hline 1 truck & 20 & pallet \\
\hline
\end{tabular}

\begin{tabular}{|l|l|l|}
\hline Symbol & Parameter & Value \\
\hline$v$ & Maintenance factor & 1 \\
\hline$c_{r \text { stour }}$ & Cost of retour & $\$ 2.00$ \\
\hline$c_{\text {oporation }}$ & Operation/unit & $\$ 0.5$ \\
\hline$c_{S l}$ & SI (smart item) $/$ unit & $\$ 50$ \\
\hline$C d$ & Loss damage cost-shipment & $\$ 1.50$ \\
\hline$c_{G S M}$ & GSM & $\$ 0.01$ \\
\hline$c_{\text {capacity }}$ & capacity & $\$ 0.25$ \\
\hline$C s$ & Production cost & $\$ 1.00$ \\
\hline$P_{S}$ & Supplier product price & $\$ 2.00$ \\
\hline$C t$ & Transport costunit & $\$ 0.05$ \\
\hline$P t$ & Transport price/unit & $\$ 0.05$ \\
\hline$c$ & Retail purchase/unit & $\$ 2.50$ \\
\hline$p$ & Retail price unit & $\$ 9.00$ \\
\hline$g$ & Shottage cost & $\$ 0.50$ \\
\hline$s$ & Salvage price & $\$ 3.5$ \\
\hline$\beta$ & Demand & 20.000 \\
\hline$b$ & Improvement rate & 0.3 \\
\hline$T c$ & Truck capacity & 10000 \\
\hline
\end{tabular}

Perusahaan masih belum menentukan jumlah pemasangan RFID pada produk buah yang akan dikirim. Semakin banyak pemasangan RFID pada tiap pengiriman akan mengakibatkan biaya RFID menjadi semakin besar namun dapat mengurangi tingkat retur/cacat produk sehingga meningkatkan kepuasan pelanggan. Perusahaan memiliki 2 pilihan yaitu,

1. Memasang RFID tiap pellet

2. Memasang RFID tiap dua box

Data perkiraan efek pemasangan tersebut dapat dilihat pada Tabel 4.
Tabel 4. Parameter yang mempengaruhi penyusutan per pallet per 2 box

\begin{tabular}{|c|c|c|c|}
\hline & & per palle & eer 2 box \\
\hline$\rho$ & Density factor & 0,002 & 0,01 \\
\hline$\omega$ & Buah yang rusak & $5 \%$ & $0,5 \%$ \\
\hline$\Psi$ & Hilang dala m pengiriman & $5 \%$ & $1 \%$ \\
\hline k & $\begin{array}{l}\text { Tingkat pengembalian } \\
\text { produk yang hilang }\end{array}$ & $90 \%$ & $95 \%$ \\
\hline$\phi$ & $\begin{array}{l}\text { Persentase kemampuan } \\
\text { sistem mendeteksi produk } \\
\text { cacat saat pengiriman }\end{array}$ & $1 \%$ & $5 \%$ \\
\hline
\end{tabular}

Tipe RFID tag termurah adalah $\$ 0,1$ dengan efek improvement sebesar 0,1 . Diasumsikan bahwa tiap kenaikan harga RFID tag sebesar $25 \%$ akan berpengaruh terhadap kenaikan improvement rate sebesar $10 \%$.

Berdasar kondisi tersebut maka :

1. Bagaimanakah analisis pengaruh jumlah pemasangan RFID terhadap profit perusahaan?

2. Pada harga RFID tag berapakah profit perusahaan menjadi optimal?

Catatan:

- Variabel keputusan $\rightarrow$ faktor yang berpengaruh dan harga RFID tag

- Keluaran $\rightarrow$ profit perusahaan

Berdasarkan kondisi kasus di atas, maka dibuatlah influence diagram (Gambar. 3) dengan faktor yang mempengaruhi dan RFID tag sebagai variabel keputusan sedangkan profit perusahaan sebagai profitnya.

Berdasarkan influence diagram, pemodelan mengenai analisa keuntungan biaya penggunaan RFID pada proses supply chain sebuah perusahaan dari lini produksi, pengiriman, dan pengecer dibuat sebagai berikut :

1. SI operation cost $=\rho{ }^{*}\left(\mathrm{CsI}^{*} \mathrm{~V}\right.$ ${ }^{*}$ C_operation) ${ }^{*}$ Qsales

Pers. 1

2. Total Cost of Retour $=\omega^{*}$ C_retour * Qsales

Pers. 2

3. Total Supplier Cost $=$ SI operational cost + Total Cost of Retour

Pers. 3

4. SI communication cost $=$ C_gsm * $(\varphi+\psi$ * $2 \mathrm{~F}$ ) * Qsales

Pers. 4

$\mathrm{F} \rightarrow$ jumlah armada yang diperlukan 
5. Shipment Loss Cost $=(1-k){ }^{*} \psi^{*}(\mathrm{~S}+$ C_capacity) * Qsales

Pers. 5

6. Transport Cost $=$ C_transport * Qsales

Pers. 6

7. Total Shipment Cost $=$ pers $4+$ pers $5+$ pers 6

Pers. 7

8. Qsales $=$

$\frac{\beta}{\alpha+b(1-\alpha)}\left(1-\frac{c+t-(\alpha+b(1-\alpha)) s}{(p+g-s)(\alpha+b(1-\alpha))}\right)$

Pers. 8

9. Retail Profit $=$

$\frac{\beta}{2}(p+g-s)\left(1-\frac{c+t-(\alpha+b(1-\alpha)) s}{(p+g-s)(\alpha+b(1-\alpha)}\right)^{2}-\frac{\beta}{2} g$

Pers. 9

10. Total Profit $=$ Retail Profit - (Total Supplier Cost + Total Shipment Cost) Pers. 10

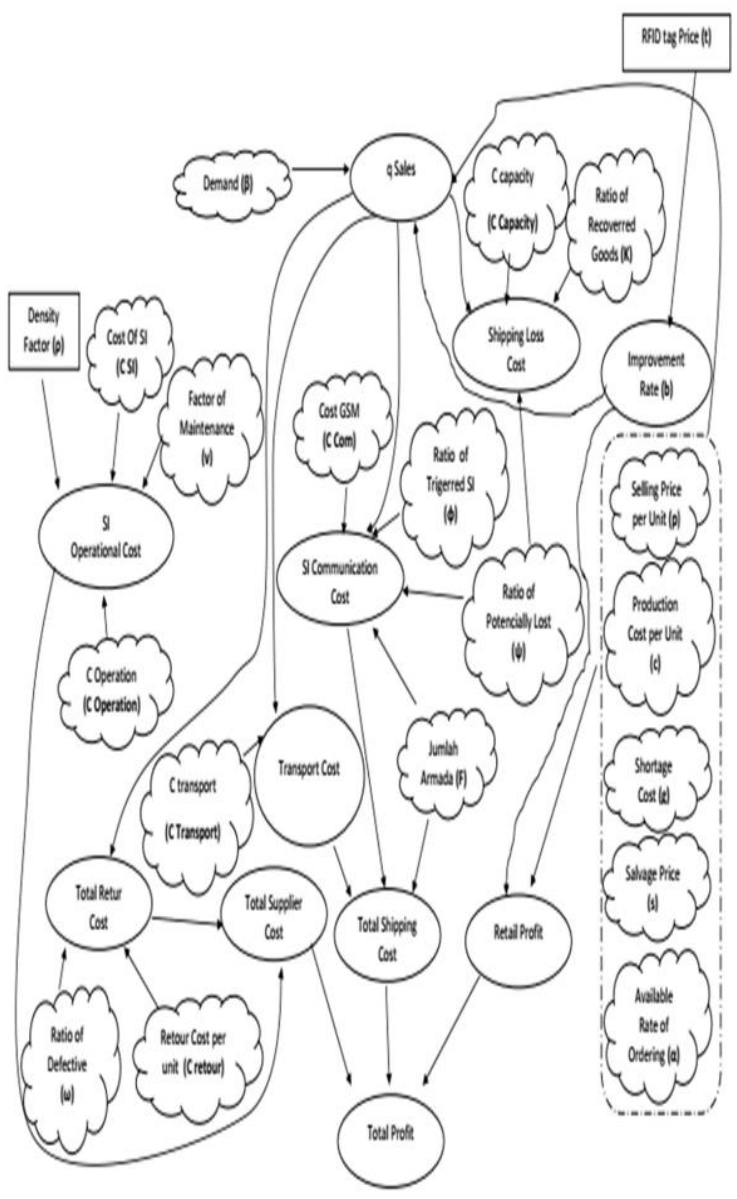

Gambar 3. Influence Diagram

Dari perhitungan penggabungan model di atas didapatkan analisis pengaruh jumlah pemasangan RFID dan pengaruh harga RFID terhadap profit perusahaan.

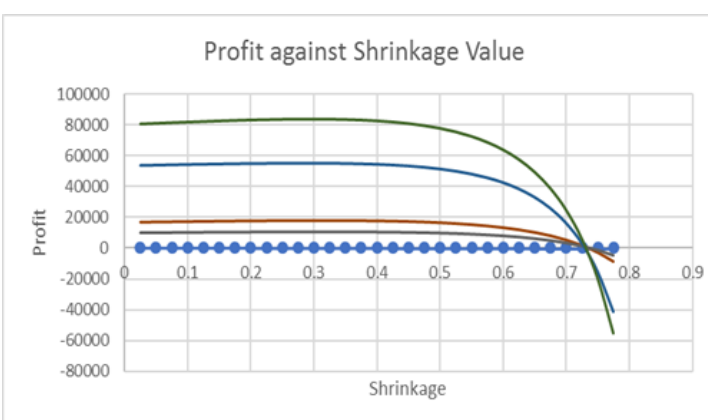

$\rightarrow-\alpha \longrightarrow$ - supplier profit $\longrightarrow$ shipper profit $\longrightarrow$ retailer profit $\longrightarrow$ Total SC benefit

Gambar 4. Pengaruh jumlah pemasangan RFID pada 2 box dan harga $R F I D$ tag terhadap profit perusahaan

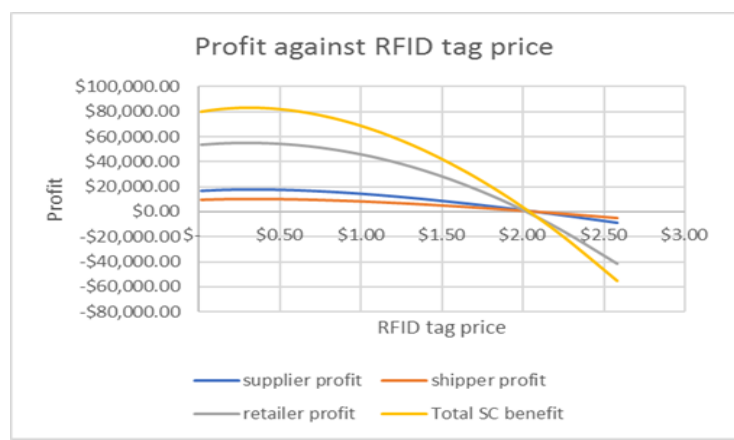

Gambar 5. Pengaruh jumlah pemasangan RFID pada pallet dan harga RFID tag terhadap profit perusahaan

\section{Kesimpulan}

Berdasarkan penelitian yang dikaji melalui studi kasus model diatas, dengan penerapan RFID mampu memberikan keuntungan atas investasi yang dilakukan dan dapat menekan biaya operational logistik, yaitu : pemasangan RFID per-pellet lebih menguntungkan bagi perusahaan. Namun pemasangan RFID per 2 box juga masih menguntungkan bagi perusahaan ditambah keuntungan berupa kepuasan pelanggan karena tingkat produk cacat hanya $0,5 \%$. Selain itu profit perusahaan menjadi optimal pada harga RFID tag $\$ 1,05$ untuk pemasangan RFID per pellet dan pada harga $\$ 1,425$ untuk pemasangan SI per 2 box. Dengan demikian, RFID mampu meningkatkan produktivitas kerja untuk terciptanya efisiensi biaya, waktu dan tenaga.

\section{Saran}


Model yang dikembangkan ini masih belum secara teliti diperiksa. Model hanya digunakan untuk contoh perhitungan dengan model tersebut. Perlu ada data riset lain yang secara empiris sudah terbukti untuk dimasukkan ke dalam model terutama untuk nilai parameterparameter. Selain faktor biaya yang dapat diimbangi, manfaat yang belum terlihat termasuk peningkatan koordinasi antar organisasi dan kepuasan pelanggan menuntut model lanjutan untuk analisis investasi RFID yang perlu dikaji peneliti di masa mendatang. Terwujudnya model ini akan mendorong terciptanya sistem rantai pasok yang lebih efisien, keterpaduan, dan pengendalian proses secara optimal dalam suatu bisnis perusahaan.

\section{Daftar Pustaka}

Decker, C., Berchtold, M., Weiss F. Chaves, L., Beigl, M., Roehr, D., Riedel, T., \& Herzig, D. (2008). Cost-Benefit Model for Smart Items in the Supply Chain. The Internet of Things, 155-172. University of Karlsruhe, Jerman.

Fan, T. J., Chang, X. Y., Gu, C. H., Yi, J. J., \& Deng, S. (2014). Benefits of RFID technology for reducing inventory shrinkage. International Journal of Production Economics, 147, 659-665. East China University of Science and Technology, Shanghai, China.

Juels, A. (2005). "RFID Security and Privacy: 28 September.

Hunt, Daniel V., Puglia, A. \& Puglia, M. (2007). RFID A guide to Radio Frequency Identification. Hoboken New Jersey: John Wiley \& Sons.

Lawal, N.T.A, Odeniyi, O.A, Gazaly-Agboola, A.B., (2016). Performance Analysis Radio Frequency Identification Technology in Management of Fashion and Food Retail Supply. International Journal of Emerging Technology and Innovative Engineering, Vol 1, Issue 7.

Rekik, Evren, S., Dallery, Y. (2009). Inventory inaccuracy in retail stores due to theft: An analysis of the benefits of RFID. International Journal of Production Economics, 118, 2009: 189-198.

Sarac, A., Absi, N., Dauzere-Peres. (2009). A Literature Review on The Impact of RFID Technologies of the Supply Chain Management. Working Paper ENSM-SE
CMP WP.

Sarac, A., Absi, N., Dauzere-Peres. (2015). A Impacts of RFID technologies on supply chains: a simulation study of a three-level supply chain subject to shrinkage and delivery errors. European J. Industrial Engineering, Vol. 9, No. 1.

Tarigan, Z, J, H. (2004). Integrasi Teknologi RFID dengan Teknologi ERP Untuk Otomatisasi Data. Jurnal Teknik Industri. 6, No.2. 2004: 134-141.

Tajima, M. (2007). Strategic value of RFID in supply chain management. Journal of Purchasing \& Supply Management, 13: 261-273.

Tao, F., Fan, T., Lai, KK. and Li, L.(2017). Impact of RFID technology on inventory control policy. Journal of the Operational Research Society, doi:10.1057/s41274-0160030-5.

Veronneau S, Roy J. (2009). RFID benefits, costs, and possibilities: the economical analysis of RFID deployment in a cruise corporation global service supply chain. Int $J$ Prod Econ 122(2):692-702.

Wu X, Yue D, Bai J, A. (2009). Real Options approach to strategic RFID investment decision. In: 2009 IEEE International conference on RFID, pp 314-321. IEEE.

Zaheeruddin Asif. (2005). Integrating the Supply Chain with RFID: A Technical and Business Analysis. Volume 15 Article 24. Communications of the Association for Information Systems is produced by The Berkeley Electronic Press (bepress). 